\title{
Effect of a Medication-Taking Behavior Feedback, Theory-Based Intervention on Outcomes in Patients with Heart Failure
}

\author{
Jia-Rong Wu, PhD, RN[Associate professor], \\ University of North Carolina at Chapel Hill, School of Nursing \\ Donna J. Corley, PhD, RN[Associate professor], \\ Eastern Kentucky University, Department of Baccalaureate \& Graduate Nursing \\ Terry A. Lennie, PhD, RN, FAAN[Associate professor], and \\ University of Kentucky, College of Nursing \\ Debra K. Moser, DNSc, RN, FAAN[Professor and Gill Endowed Chair of Nursing] \\ University of Kentucky, College of Nursing
}

\begin{abstract}
BACKGROUND-Medication nonadherence contributes to hospitalization and mortality, yet there have been few interventions tested that improve adherence and reduce hospitalization and mortality in heart failure (HF).
\end{abstract}

OBJECTIVE-To determine whether an education intervention improved medication adherence and cardiac event-free survival.

\begin{abstract}
METHODS-A randomized controlled trial was conducted on $82 \mathrm{HF}$ patients. The intervention was based on the Theory of Planned Behavior (TPB) and included feedback of medication-taking behavior using the Medication Event Monitoring System (MEMS). Patients were assigned to one of three groups: 1) theory-based education plus MEMS feedback (PLUS), 2) theory-based education only (LITE), or 3) a usual care control group. Cardiac events were collected for 9 months.
\end{abstract}

RESULTS-Patients in both intervention groups were more adherent over follow-up compared to control group. In Cox regression, patients in either intervention group had a longer event-free survival compared to those in the control group before and after controlling age, marital status, financial status, ejection fraction, New York Heart Association functional class, angiotensinconverting enzyme inhibitor use, and presence or absence of a significant other during the intervention $(p<.05)$.

CONCLUSION-Use of an intervention based on the TPB improves medication adherence and outcomes in patients with HF, and as such, offers promise as a clinically applicable intervention to help patients with $\mathrm{HF}$ adhere to their prescribed regimen.

(C) 2011 Elsevier Inc. All rights reserved.

Address for correspondence: Jia-Rong Wu, PhD, RN, University of North Carolina at Chapel Hill, School of Nursing, 435 Carrington Hall, CB\# 7460, Chapel Hill, NC 27599-7460, Phone 919-966-8057, Fax 919-843-9900, jiarongw@email.unc.edu.

DISCLOSURES

We have nothing to disclose.

Publisher's Disclaimer: This is a PDF file of an unedited manuscript that has been accepted for publication. As a service to our customers we are providing this early version of the manuscript. The manuscript will undergo copyediting, typesetting, and review of the resulting proof before it is published in its final citable form. Please note that during the production process errors may be discovered which could affect the content, and all legal disclaimers that apply to the journal pertain. 


\section{Keywords}

medication adherence; intervention; randomized control trial; heart failure; outcomes; MEMS feedback; theory of planned behavior

\section{Introduction}

Heart failure (HF) currently affects 5.8 million Americans and its prevalence and incidence are increasing in the United States and worldwide. ${ }^{1,2}$ It is essential that patients with HF receive pharmacological treatment to slow cardiac remodeling, and decrease symptoms, hospitalizations and death. ${ }^{3-5}$ Prescribed therapy is, however, useless unless patients adhere to their prescribed medications. ${ }^{6}$ Medication nonadherence compromises treatment outcomes in HF. ${ }^{6-11}$ Overall medication adherence rates in HF patients average only about $50 \%^{12-21}$ and decline over time..$^{22,23}$

Due to the importance of medication adherence to hospitalization and mortality, it is vital that clinicians implement interventions to improve medication adherence. Specialized disease management programs that include medication adherence among their many targets have reduced hospitalization and mortality in $\mathrm{HF},{ }^{24,} 25$ however, the vast majority of patients do not receive care in disease management programs. There are few successful stand-alone interventions that enhance medication adherence and reduce hospitalization and mortality in HF. ${ }^{26,27}$ Moreover, there are no specific recommendations regarding the type, amount or content of information needed to increase adherence.

A theoretical model enhances understanding of complex situations. ${ }^{28}$ Without a full, rational appraisal of the problem, interventions might easily address inappropriate variables and tackle only a small proportion of the variables required to have the desired effect. ${ }^{28}$ Current approaches rarely are theory driven, resulting in interventions derived not from successful behavior change theories, but from individual practitioner's experience of best practices. A theory provides the basis for judging whether all of the necessary fundamentals of an intervention are in place. ${ }^{28}$ The Theory of Planned Behavior (TPB) is a widely used theoretical framework for explaining health-related behaviors and behavior change. ${ }^{29}, 30$ Interventions based on the TPB have been shown to be effective in improving health-related behaviors (e.g., medication adherence) in HIV-infected patients, ${ }^{30}$ stroke patients ${ }^{31}$ and diabetics. ${ }^{32}$

An additional factor that may enhance adherence is feedback of patients' adherence levels. Because patients commonly overestimate adherence and are unaware of their actual medication-taking behaviors, ${ }^{11}$ feedback of medication-taking behavior (using data from the medication event monitoring system [MEMS]) may provide an innovative approach to correct misperceptions and thus improve adherence. ${ }^{30,33-36}$ Direct feedback from the MEMS of patient actual medication-taking behavior may be a tangible method of helping patients with HF understands their own behavior. Patients' barriers to adhering to their medication may be more easily identified through discussion of missed doses from the MEMS reports. Accordingly, the purpose of this study was to determine whether a theorybased intervention that includes personalized feedback of medication-taking behavior delivered by a nurse improves adherence, decreases cardiac-related hospitalization and death, and improves quality of life in patients with HF. 


\section{METHODS}

\section{Study Design}

This study was a randomized controlled trial to determine the effect of a theory-based intervention on medication adherence and cardiac event-free survival in patients with HF. All patients were randomly assigned to the PLUS (theory-based intervention plus feedback of medication-taking behavior from the MEMS), LITE (theory-based intervention only) or a usual care control group. Patients assigned to the PLUS and LITE groups received individualized teaching and counseling. All patients used the MEMS for 9 months to monitor adherence (baseline to the end of the study [9 months]) and were followed monthly by phone to obtain their hospitalization data (by a research associate blind to group assignment from baseline to the end of the study). There was a 1 month "run in" period prior to starting the intervention to determine patients' baseline medication adherence levels.

\section{Sample and Setting}

Patients were recruited from the outpatient cardiology clinic and inpatient hospital in one Southern state. Patients who met the following selection criteria and agreed to participate were enrolled: (1) diagnosis of chronic HF (from either preserved or non-preserved systolic functions because medication adherence is an important problem in patients with both preserved and non-preserved systolic function); (2) undergone evaluation of HF by a cardiologist and optimization of medical therapy, defined as being on stable doses of HF medications for one month; and (3) able to read and speak English. Patients were excluded if they had: (1) impaired cognition defined as a word recall score of 0 or a word recall of $\leq 2$ with an abnormal clock test on the Mini-Cog Exam; (2) a co-existing imminently terminal illness such as cancer or chronic renal failure requiring dialysis; (3) a myocardial infarction within the past 3 months; or (4) a history of cerebral vascular accident within the past 3 months or with major sequelae. We excluded patients who had had an MI or a stroke within the past 3 months because their health outcomes may differ regardless of adherence.

\section{Measurement of Variables}

Cardiac event-free survival: Cardiac event-free survival was the composite end-point. This end-point consisted of cardiac-related emergency department (ED) visit, cardiac-related hospitalization, or cardiac death. We collected date and reasons for ED visits and hospitalization by making monthly follow-up phone calls to patients and confirmed these by reviewing hospital medical records. Date and cause of death were collected from interviews with family members and physicians, and were confirmed by review of medical records and death certificates.

Quality of life: Quality of life was measured using the Minnesota Living with Heart Failure Questionnaire (LHFQ). ${ }^{37,} 38$ The LHFQ was developed specifically to measure patients' perception of how much their HF and its treatment affect their ability to live as desired. It has been widely used in research and clinical practice. ${ }^{37,38}$ It consists of 21 questions rated on a scale from 0 (no effect) to 5 (very much). Item ratings are summed for a total score that can range from 0 to 105 . Higher scores reflect worse quality of life. Questions concern a variety of physical and psychological aspects of living with HF and include activities of daily living, economic issues, ability to work, enjoyment of leisure time activities, relations with family and friends, sexual activity, side effects from medications, depression, and impact of HF symptoms. The LHFQ has been used extensively in HF research and is appealing because it is inexpensive, short, easily understood by ill and elderly individuals, self-administered, and easy to score. ${ }^{37,38}$ The LHFQ has strong evidence of internal consistency reliability, with Cronbach's alphas ranging from .88 to .93 and supported 
construct validity. ${ }^{38}$ In this study, the Cronbach's alpha of the LHFQ was .94, indicating acceptable internal consistency.

Medication adherence: Medication adherence was measured using the MEMS. ${ }^{39}, 40$ The MEMS is a medication bottle with a cap that is equipped with a microchip that registers the date and time of each cap opening. ${ }^{39-41}$ The MEMS device has been demonstrated to be a valid and objective method to assess medication adherence. ${ }^{42}$ The MEMS was used to collect data on one HF medication ( $\beta$-blocker, angiotensin-converting-enzyme [ACE] inhibitor, angiotensin receptor blocker [ARB], aldosterone antagonist, digoxin, or diuretic) for each patient. The medication to be monitored was chosen based on the following criteria. If the patient was taking a medication twice a day, this medication was chosen for monitoring using the MEMS. If all medications were taken twice or only once daily, then, the beta-adrenergic blocking agent was chosen unless the patient was not prescribed one. In those cases, the ACE inhibitor or ARB was used. If no beta-blocker, ACE inhibitor, or ARB was prescribed, an aldosterone antagonist, digoxin or a diuretic was used in the MEMS device. Patients were given a MEMS diary to record unscheduled cap openings, such as those to refill the bottle, so that those unscheduled events which are unrelated to adherence were removed from analysis. Medication adherence from the MEMS was defined as the dose-count which is the percentage of prescribed doses taken during the 9-month monitoring period. ${ }^{11}$

In this study, we chose $88 \%$ as the cutpoint to categorize patients into adherent or nonadherent. Patients who took $\geq 88 \%$ of their prescribed doses were categorized as adherent, while patients who took less than $88 \%$ of doses were categorized as non-adherent. This cutpoint was chosen based on our prior research demonstrating that $\geq 88 \%$ is an evidence-based (as opposed to arbitrary) cutpoint to define adherence based on outcomes. ${ }^{43}$

Other variables of interest: To characterize subjects and obtain data on potential confounding variables, information concerning the following variables was collected from the medical records, or patient interview: age, gender, marital status, years of education, left ventricular ejection fraction, medication regimen, and presence or absence of a significant other during the intervention. New York Heart Association (NYHA) functional class was determined by standardized patient interview. ${ }^{44}$ Self-reported financial status was assessed using one item from our socio-demographic questionnaire. Patients were asked to rate "Considering how well your household lives on its income. Financially, would you say you are: (1) Comfortable; have more than enough to make ends meet; (2) Have enough to make ends meet; or (3) Do not have enough to make ends meet." Lower scores indicated better reported financial status.

INTERVENTION-The TPB is an effective behavior change theory to support an intervention designed to increase medication adherence. ${ }^{29}$ According to the TPB the proximate determinant of actual behavior is a person's behavioral intention or his/her intention to engage in the target behavior. ${ }^{29}$ The direct determinants of behavioral intention are attitudes (patient's beliefs about outcomes of adhering prescribed medication), subjective norm (whether patient's significant others and physicians approve or disapprove of medication adherence), and perceived behavioral control (the presence or absence of resources for, and impediments to, performance of adhering prescribed medication). ${ }^{29}$ Patients' significant others were patients' spouse, daughters/sons, relatives, neighbors or friends who might or might not live with the patients in the same house, but who took care of patients and were identified by patients as their major caretakers. Our intervention is designed to encourage positive behavioral beliefs by explaining the significance of HF symptoms, their relationship with $\mathrm{HF}$ and the importance of adhering to medications (attitudes). The intervention encourages identification of significant others and reflection by 
patients of their beliefs about significant others' opinions on whether it is important for patients to take prescribed medication regularly (subjective norm). Significant others who participate in the intervention are taught how to support the patient by emphasizing the importance of adherence and identify what they can help in improving medication adherence through facilitating communication between patient and significant others (subjective norm). Resources that support or impede adherence are identified by interventionist and the patient and/or significant others, teaching is individualized to increase perceived control, and patients are taught the skills needed to feel empowered (perceived behavioral control). The provision of feedback about patients' medication taking behavior is used to identify their barriers to adherence through discussion of missed doses from their MEMS reports (perceived behavioral control).

The intervention was delivered by a cardiovascular nurse expert (JRW) in delivery of the education and counseling intervention. Patients in both the PLUS and LITE groups received the following education and counseling intervention. The intervention is delivered individually every other week for a total of 4 sessions. The first and third sessions were faceto-face education and counseling lasting about one hour. The second and four sessions were delivered by telephone lasting about 15-20 minutes each. The intervention was designed to influence medication adherence by creating a more positive attitude toward medication adherence, incorporating significant others into the patient education and counseling sessions to build a positive subjective norm, and providing needed information and skills to overcome barriers to adherence to increase the patient's perceived behavioral control.

PLUS group: Patients in the PLUS group received feedback of their medication-taking behavior from the MEMS at each of the two face to face intervention sessions (Sessions $1 \&$ 3). MEMS feedback was used to show patients their own medication-taking behavior in order to correct any misperceptions of actual adherence and to identify problem areas (e.g., reasons of missing certain doses). A visual display of adherence behavior from the MEMS report was shared by the nurse with the patient. The purpose of this feedback was to give patients insight into their own medication-taking behavior over time, to increase their perceived behavioral control and improve medication adherence and outcomes.

Procedure: See Table 1. Permission to conduct this study was obtained from appropriate Institutional Review Board. Patients were referred to the investigator by physicians or nurse practitioners. Patient eligibility was confirmed by a trained nurse who then explained study requirements to the patients and invited them to participate. At baseline, after obtaining an informed consent, patient's demographic and clinical characteristics were collected by interview and medical record review. Patients completed the questionnaires and were provided detailed written and verbal instructions on use of the MEMS bottle for the onemonth run-in period. A second appointment was made one month later. At this visit, a research nurse determined patient's adherence rate by downloading data from the MEMS. Patients were categorized as adherent (i.e. $\geq 88 \%$ medication adherence) or non-adherent (i.e. $<88 \%$ medication adherence). ${ }^{43}$

All patients were stratified by medication adherence (using $88 \%$ as cutpoint) and then randomized to one of the three groups. For those patients randomized to either the PLUS or LITE groups, this visit also included the first intervention session. For patients in the control group, this session ended after data collection. All patients continued to use the MEMS for 9 months from baseline. Patients in all groups received monthly phone calls to ask about any ED visits and/or hospitalizations. At 9 months, all patients had the last visit to complete questionnaires and returned MEMS cap, the diary that recorded unscheduled cap openings, and a list of ED visits and/or hospitalizations. 
Data Analysis-All data analyses were performed using SPSS, version 17.0; an alpha level of $<0.05$ was used. The analyses followed an intent-to-treat strategy. That is, the analyses included all participants in the groups to which they were randomly assigned, regardless of their level of adherence to the intervention and regardless of subsequent withdrawal from the study. To compare time to first cardiac event among the 3 groups, Kaplan-Meier plots were used to graphically depict group differences in time to first cardiac event, and log-rank tests were used to determine which group of patients had the longer event-free survival time. Cox proportional hazards regression modeling was used to assess this endpoint, while controlling for appropriate demographic and clinical variables, including age, marital status, financial status, ejection fraction, baseline NYHA, ACE inhibitor use, and presence or absence of a significant other during the intervention. Repeated measure analysis of variance (ANOVA) was used to compare quality of life and medication adherence among 3 groups over the 9 month period. Both continuous data and dichotomized data (using $88 \%$ as cutpoint) of medication adherence were used in the separate analyses. Post-hoc comparisons based on Fisher's least significant difference (LSD) procedure were used to determine how the three groups differed at each time point.

\section{RESULTS}

\section{Patient Characteristics}

Of the 195 eligible HF patients approached for the study; 110 patients refused to participate due to long travel distance, time concerns (e.g., have to take care of other family members), no interest in participating in research, or lack of energy. Three patients withdrew from the study before randomization due to moving to an assisted facility $(n=2)$ and dealing with another medical condition $(n=1)$. A total of 82 patients with HF were included in this study. The mean age of patients was $60 \pm 13$ years. Half of the patients had advanced HF as reflected by their NYHA functional class. The average left ventricular ejection fraction reflected the enrollment of both patients with and without preserved systolic function. Less than one third of the patients were defined as non-adherent based on $88 \%$ cutpoint. Full sample characteristics and comparisons among the 3 groups are presented in Table 2 . Groups did not differ on clinical characteristics at baseline; however, there were a greater percentage of married patients in the intervention groups (70\%) than in the control group (39\%). Therefore, we adjusted for marital status in the Cox regression.

\section{Intervention effect on event-free survival}

Kaplan Meier survival curve and log-rank test-Kaplan-Meier plots with log-rank tests were used to compare patients' time to first occurrence of the composite endpoint among the 2 intervention groups and the control group. Kaplan-Meier survival analysis demonstrated that there was a significant difference on event-free survival among 3 groups $(\mathrm{p}=.034$, Figure 1). The PLUS and LITE groups did not differ on event-free survival, thus data of the 2 intervention groups were combined. Event-free survival was significantly longer for the patients in both intervention groups than those in the control group $(p=.01$, Figure 2).

Cox regression modeling - In Cox regression (Table 3), group assignment (intervention vs. control) was a predictor of cardiac event-free survival before and after controlling age, marital status, financial status, ejection fraction, baseline NYHA class, ACE inhibitor use, and presence or absence of a significant other during the intervention $(p<.05)$. The hazard ratio for time to the first cardiac event for patients assigned to the control group was 2.91 compared to those assigned to the intervention groups. The hazard ratio for time to the first cardiac event for patients in the control group increased to 4.22 after controlling for some socio-demographic (age, marital status, financial status), clinical factors (ejection fraction, 
baseline NYHA functional class, angiotensin-converting enzyme inhibitor use), and presence or absence of a significant other during the intervention compared with those in the intervention groups. In addition to group assignment, financial status and baseline NYHA functional class were independent predictors of the composite endpoint $(p<.05)$. Patients who had low financial status (i.e., those who did not have enough to make ends meet) had 5.16 odds greater odds of having a cardiac event than those who had better financial status (i.e., those who reported to have more than enough to make ends meet). Patients in NYHA III or IV were 3.16 times more likely to experience a cardiac event compared to patients in NYHA I or II.

\section{Intervention effect on quality of life}

The mean quality of life score measured by the LHFQ was 37.5 at baseline. There was no difference in quality of life scores among the 3 groups at baseline. Figure 3 shows quality of life trajectory for each group over the 9 month period. Repeated measure ANOVA showed no main effect for time or group by time interaction. Although there appears to be a trend for quality of life to improve over time for patients in the intervention groups, this trend was not significant.

\section{Intervention effect on medication adherence}

Adherence was determined on a medication taken twice daily in a majority $(77 \%)$ of patients. Medication adherence (Table 2) measured by the MEMS showed a mean medication adherence of $93.9 \%$ at baseline. There was no difference in medication adherence among 3 groups at baseline $(p=.255)$. Figure 4 shows medication adherence trajectory for each of the 3 groups from baseline to the end of the 9-month follow-up period. Repeated measure ANOVA showed that there was a significant interaction for group by time $(\mathrm{F}=2.686, p=.049)$. There were significant differences in medication adherence from baseline to 2 months and to 9 months among the 3 groups. Patients who were in the PLUS group had better medication adherence compared to those in the control group at 2 months $(\mathrm{p}=.05)$ and at 9 months $(p=.021)$. There was a difference in medication adherence between the LITE and control group at 9 months $(p=.04)$, but not between the LITE and control group at 2 months $(p=.143)$, nor the PLUS and LITE groups at 2 months $(p=.668)$ or 9 months $(p=.804)$.

Patients were classified at baseline as adherent if their medication adherence rate achieved $\geq$ $88 \%$ and as nonadherent if $<88 \%$. At baseline, there were no differences among 3 groups for number of adherent patients based on chi square test $(p=.694)$. There were similar percentages of patients who were adherent among 3 groups (70\% in PLUS group, 59\% in LITE group, and 64\% in the control group, Table 4). During the intervention period, more patients in the intervention groups (PLUS and LITE groups) became adherent compared to those in the control group. At 9 months, the percentage of adherent patients dropped slightly in the intervention groups. However, in the control group, the percentage of adherent patients dropped from $64 \%$ at baseline, to $59 \%$ at 2 months and to $36 \%$ at 9 months. There were significantly more patients in the intervention groups (PLUS and LITE) who remained above the adherence level at 9 months compared to those in the control group (74\%, 65\%, and $36 \%$ for PLUS, LITE, and control group, respectively, $p=.015$, Table 4 ).

\section{DISCUSSION}

In this study, we tested an innovative intervention designed to enhance medication adherence. We demonstrated that patients in either of the intervention groups had better medication adherence and a longer event-free survival compared to patients in the control group who received usual care. The estimated medical costs for HF for 2010 are $\$ 39.2$ 
billion and are continuing to rise. ${ }^{2}$ Medication nonadherence resulting in HF exacerbation and subsequent hospital readmission is the most common cause of high health care costs, $, 8,10,45$ demonstrating how important it is to discover effective interventions to improve adherence. ${ }^{7-11}$

Our study needs to be considered in light of the findings from similar studies. To date, there have been seven investigations testing the impact of interventions designed to improve medication adherence on adherence and outcomes in patients with HF. $5,26,27,46-49$ In all studies, 5, 26, 27, 46-49 adherence rates improved in the intervention compared to control group, but outcomes were improved in only four..$^{5,26,27,48}$ In the other three studies, $46,47,49$ no change in hospitalization or mortality was noted between the intervention and usual care groups. Potential reasons for failure to demonstrate a difference in outcomes, despite an increase in adherence, include: (1) short follow-up period ${ }^{46,49}$ and 2) use of selfreport measure, which is subject to reporting bias. ${ }^{47}$

Among the four studies in which outcomes were better in the intervention group, in only one was the MEMS used to assess medication adherence. The intervention lasted nine months, and involved an interdisciplinary team. ${ }^{27}$ The effects of the intervention were evident only during the intervention period. The intensity of the intervention and the limited effectiveness suggested that the intervention would not be sustainable in usual practice settings. The remaining three studies in this group were limited by the use of self-report to measure adherence. ${ }^{5,26,48}$ Self-report is subject to recall bias and social desirability.

In our study, the mean medication adherence of patients in the control group was $94.5 \%$ at baseline; however, the rate dropped to $90.7 \%$ at 2 months and dropped even more to $84.2 \%$ at 9 months. The finding was consistent with the previous study, medication adherence rate decreases as time progresses. ${ }^{22,23}$ To our knowledge, this is the first study to explore the natural pattern of medication adherence over 9 months in patients with HF. It is important to note that two thirds of patients in the control group were adherent using the cutpoint of $88 \%$ at baseline. However, the number of adherent patients dropped dramatically in the control group. The number of adherent patients was maintained over the 9 months in the intervention groups. Therefore, even patients who were adherent at baseline still need interventions and/or reminders to help them sustain their adherence level.

Post hoc test showed there was a difference in medication adherence between the PLUS and control group at 2 months and 9 months, but not PLUS and LITE groups. We also did not find a difference between PLUS group and LITE group in cardiac event-free survival. In previous studies MEMS report as feedback for medication-taking behavior was effective in improving medication adherence of HIV positive, ${ }^{30}$ smoking (adherence to bupropion), ${ }^{50}$ and hypertensive ${ }^{33}$ individuals and people with diabetes. ${ }^{36}$ It is unclear why we could not find a difference between PLUS and LITE groups. There are a few possibilities. First, feedback from the MEMS is to help patients with HF to understand their actual medicationtaking behavior and track back on those days they missed doses. Then, it will be easier to help patients recognize their barriers of missing doses and find ways to target on those barriers. However, patients may have established and known their patterns of taking their medication and their reasons of missed doses without the help from a MEMS report.

Second is dose response. In the most effective studies, patients in the intervention group received more sessions of feedback intervention ( 3 to 7 sessions) than our study. It might take more than two sessions of feedback intervention to see their medication-taking patterns, identify the reasons of missed doses, and gain skills to adhere to their medications. Third, in $t_{w o}{ }^{30,36}$ of the effective feedback studies, patients in the intervention group were offered another type of MEMS caps during the intervention: the so-called SmartCap that displays 
how often it has been opened during that day and helps patients to increase their adherence. No matter which possibility is correct, the findings need to be verified in a larger sample size and recruiting more non-adherent patients in the future study.

\section{Limitation}

Our findings should be interpreted with the following limitations in mind. First, it is assumed that patients take one dose of their prescribed medication after each MEMS bottle opening although this assumption could be questioned. The MEMS device is a valid, objective, and considered a "gold standard" measure to assess medication adherence in the current adherence literature. ${ }^{42}$ Prior researchers have demonstrated that opening of the bottle does, indeed, reflect actual medication taking, ${ }^{31,34}$ and that use of the MEMS does not increase adherence artificially. ${ }^{35}$ However, we did not measure serum drug levels and cannot say with absolute certainty that when patients opened the MEMS cap, that they really took out the medication and consumed it. Our finding, however, of an association between increased medication adherence and improved outcomes make this likelihood quite small.

Another potential limitation has to do with the applicability of the MEMS to clinical practice. The use of the MEMS to measure medication adherence is likely too expensive and not practical in the clinical settings. Therefore, even though self-report measures are subject to recall bias and social desirability, it is important to develop a reliable and valid self-report instrument to measure medication adherence for researchers and clinicians in order to translate the results of this study to clinical settings.

Although we demonstrated significant differences (better medication adherence and less cardiac event) between intervention and control groups, a larger sample size of non-adherent HF patients is needed to generalize these results. This study had a total sample of 82 participants who were recruited from one Southern tertiary hospital. Our sample only included 36\% non-adherent patients. Therefore, findings from this study warrant further study in a larger non-adherent sample. Finally, there were more married patients randomized to the intervention group than to the control group, and for this reason we adjusted for marital status in the multiple Cox regression.

\section{CONCLUSION}

We provided evidence that use of an intervention based on the TPB improved medication adherence and reduced cardiac events in patients with HF. Heart failure is a chronic condition and requires patients to take their several medications on a daily basis indefinitely. It is important for clinicians to implement interventions to help patients with HF to adhere to their prescribed on a regular basis. Our theory-based intervention is a clinically applicable approach that clinicians can use. One possible way to transfer the intervention to the clinical setting is to train home health nurses to deliver the intervention.

We further provided evidence that medication adherence decreases over time regardless of whether patients are adherent on first assessment or not. Thus, it is essential that clinicians assess adherence at each visit, even when patients appear to have been adherent in the past.

\section{Acknowledgments}

This study was supported by funding from the Philips Medical-American Association of Critical Care Nurses Outcomes Grant (Dr. Jia-Rong Wu, principal investigator), American Heart Association Great River Affiliate Postdoctoral Fellowship to Jia-Rong Wu (Dr. Debra K. Moser, mentor), and a Center grant to the University of Kentucky, College of Nursing from NIH, NINR, 1P20NR010679. 


\section{Literature Cited}

1. van Jaarsveld CH, Ranchor AV, Kempen GI, Coyne JC, van Veldhuisen DJ, Sanderman R. Epidemiology of heart failure in a community-based study of subjects aged $>$ or $=57$ years: Incidence and long-term survival. Eur J Heart Fail. 2006; 8:23-30. [PubMed: 16209932]

2. Lloyd-Jones D, Adams RJ, Brown TM, Carnethon M, Dai S, De Simone G, Ferguson TB, Ford E, Furie K, Gillespie C, Go A, Greenlund K, Haase N, Hailpern S, Ho PM, Howard V, Kissela B, Kittner S, Lackland D, Lisabeth L, Marelli A, McDermott MM, Meigs J, Mozaffarian D, Mussolino M, Nichol G, Roger VL, Rosamond W, Sacco R, Sorlie P, Stafford R, Thom T, WasserthielSmoller S, Wong ND, Wylie-Rosett J. Heart disease and stroke statistics--2010 update: A report from the american heart association. Circulation. 2010; 121:e46-e215. [PubMed: 20019324]

3. Stanley M, Prasun M. Heart failure in older adults: Keys to successful management. AACN Clin Issues. 2002; 13:94-102. [PubMed: 11852727]

4. Cleland JG, Clark A. Has the survival of the heart failure population changed? Lessons from trials. Am J Cardiol. 1999; 83:112D-119D. [PubMed: 10073796]

5. Sadik A, Yousif M, McElnay JC. Pharmaceutical care of patients with heart failure. Br J Clin Pharmacol. 2005; 60:183-193. [PubMed: 16042672]

6. De Geest S, Sabate E. Adherence to long-term therapies: Evidence for action. Eur J Cardiovasc Nurs. 2003; 2:323. [PubMed: 14667488]

7. Chin MH, Goldman L. Factors contributing to the hospitalization of patients with congestive heart failure. Am J Public Health. 1997; 87:643-648. [PubMed: 9146445]

8. Li H, Morrow-Howell N, Proctor EK. Post-acute home care and hospital readmission of elderly patients with congestive heart failure. Health Soc Work. 2004; 29:275-285. [PubMed: 15575455]

9. Miura T, Kojima R, Mizutani M, Shiga Y, Takatsu F, Suzuki Y. Effect of digoxin noncompliance on hospitalization and mortality in patients with heart failure in long-term therapy: A prospective cohort study. Eur J Clin Pharmacol. 2001; 57:77-83. [PubMed: 11372597]

10. Hope CJ, Wu J, Tu W, Young J, Murray MD. Association of medication adherence, knowledge, and skills with emergency department visits by adults 50 years or older with congestive heart failure. Am J Health Syst Pharm. 2004; 61:2043-2049. [PubMed: 15509127]

11. Wu JR, Moser DK, Chung ML, Lennie TA. Objectively measured, but not self-reported, medication adherence independently predicts event-free survival in patients with heart failure. $\mathrm{J}$ Card Fail. 2008; 14:203-210. [PubMed: 18381183]

12. Col N, Fanale JE, Kronholm P. The role of medication noncompliance and adverse drug reactions in hospitalizations of the elderly. Arch Intern Med. 1990; 150:841-845. [PubMed: 2327844]

13. Huang LH. Medication-taking behavior of the elderly. Kaohsiung J Med Sci. 1996; 12:423-433. [PubMed: 8753145]

14. Cline CM, Bjorck-Linne AK, Israelsson BY, Willenheimer RB, Erhardt LR. Non-compliance and knowledge of prescribed medication in elderly patients with heart failure. Eur J Heart Fail. 1999; 1:145-149. [PubMed: 10937924]

15. Blenkiron P. The elderly and their medication: Understanding and compliance in a family practice. Postgrad Med J. 1996; 72:671-676. [PubMed: 8944209]

16. Rodgers PT, Ruffin DM. Medication nonadherence: Part ii--a pilot study in patients with congestive heart failure. Manag Care Interface. 1998; 11:67-69. 75. [PubMed: 10187590]

17. Bonner CJ, Carr B. Medication compliance problems in general practice: Detection and intervention by pharmacists and doctors. Aust J Rural Health. 2002; 10:33-38. [PubMed: 11952520]

18. Graveley EA, Oseasohn CS. Multiple drug regimens: Medication compliance among veterans 65 years and older. Res Nurs Health. 1991; 14:51-58. [PubMed: 2017581]

19. Monane M, Bohn RL, Gurwitz JH, Glynn RJ, Avorn J. Noncompliance with congestive heart failure therapy in the elderly. Arch Intern Med. 1994; 154:433-437. [PubMed: 8117176]

20. Artinian NT, Harden JK, Kronenberg MW, Vander Wal JS, Daher E, Stephens Q, Bazzi RI. Pilot study of a web-based compliance monitoring device for patients with congestive heart failure. Heart Lung. 2003; 32:226-233. [PubMed: 12891162] 
21. Evangelista LS, Berg J, Dracup K. Relationship between psychosocial variables and compliance in patients with heart failure. Heart Lung. 2001; 30:294-301. [PubMed: 11449216]

22. Butler J, Arbogast PG, Daugherty J, Jain MK, Ray WA, Griffin MR. Outpatient utilization of angiotensin-converting enzyme inhibitors among heart failure patients after hospital discharge. $\mathrm{J}$ Am Coll Cardiol. 2004; 43:2036-2043. [PubMed: 15172409]

23. DiMatteo MR, Sherbourne CD, Hays RD, Ordway L, Kravitz RL, McGlynn EA, Kaplan S, Rogers WH. Physicians' characteristics influence patients' adherence to medical treatment: Results from the medical outcomes study. Health Psychol. 1993; 12:93-102. [PubMed: 8500445]

24. Gohler A, Januzzi JL, Worrell SS, Osterziel KJ, Gazelle GS, Dietz R, Siebert U. A systematic meta-analysis of the efficacy and heterogeneity of disease management programs in congestive heart failure. J Card Fail. 2006; 12:554-567. [PubMed: 16952790]

25. Gonseth J, Guallar-Castillon P, Banegas JR, Rodriguez-Artalejo F. The effectiveness of disease management programmes in reducing hospital readmission in older patients with heart failure: A systematic review and meta-analysis of published reports. Eur Heart J. 2004; 25:1570-1595. [PubMed: 15351157]

26. Barnason S, Zimmerman L, Hertzog M, Schulz P. Pilot testing of a medication self-management transition intervention for heart failure patients. West J Nurs Res. 2010; 32:849-870. [PubMed: 20702679]

27. Murray MD, Young J, Hoke S, Tu W, Weiner M, Morrow D, Stroupe KT, Wu J, Clark D, Smith F, Gradus-Pizlo I, Weinberger M, Brater DC. Pharmacist intervention to improve medication adherence in heart failure: A randomized trial. Ann Intern Med. 2007; 146:714-725. [PubMed: 17502632]

28. Green J. The role of theory in evidence-based health promotion practice. Health Educ Res. 2000; 15:125-129. [PubMed: 10751371]

29. Glanz, K.; Rimer, BK.; Viswanath, K. Health behavior and health education: Theory research and practice. San Francisco: Jossey-Bass; 2008.

30. de Bruin M, Hospers HJ, van den Borne HW, Kok G, Prins JM. Theory- and evidence-based intervention to improve adherence to antiretroviral therapy among hiv-infected patients in the netherlands: A pilot study. Aids Patient Care STDS. 2005; 19:384-394. [PubMed: 15989434]

31. Bonetti, D.; Johnston, M. Br J Health Psychol. 2007. Perceived control predicting the recovery of individual-specific walking behaviours following stroke: Testing psychological models and constructs.

32. Gucciardi E, Demelo M, Lee RN, Grace SL. Assessment of two culturally competent diabetes education methods: Individual versus individual plus group education in canadian portuguese adults with type 2 diabetes. Ethn Health. 2007; 12:163-187. [PubMed: 17364900]

33. Brunenberg DE, Wetzels GE, Nelemans PJ, Dirksen CD, Severens JL, Stoffers HE, Schouten JS, Prins MH, de Leeuw PW, Joore MA. Cost effectiveness of an adherence-improving programme in hypertensive patients. Pharmacoeconomics. 2007; 25:239-251. [PubMed: 17335309]

34. Rigsby MO, Rosen MI, Beauvais JE, Cramer JA, Rainey PM, O’Malley SS, Dieckhaus KD, Rounsaville BJ. Cue-dose training with monetary reinforcement: Pilot study of an antiretroviral adherence intervention. J Gen Intern Med. 2000; 15:841-847. [PubMed: 11119180]

35. Rosen MI, Dieckhaus K, McMahon TJ, Valdes B, Petry NM, Cramer J, Rounsaville B. Improved adherence with contingency management. Aids Patient Care STDS. 2007; 21:30-40. [PubMed: 17263651]

36. Rosen MI, Rigsby MO, Salahi JT, Ryan CE, Cramer JA. Electronic monitoring and counseling to improve medication adherence. Behav Res Ther. 2004; 42:409-422. [PubMed: 14998735]

37. Rector TS, Tschumperlin LK, Kubo SH, Bank AJ, Francis GS, McDonald KM, Keeler CA, Silver MA. Use of the living with heart failure questionnaire to ascertain patients' perspectives on improvement in quality of life versus risk of drug-induced death. J Card Fail. 1995; 1:201-206. [PubMed: 9420652]

38. Rector TS, Cohn JN. Assessment of patient outcome with the minnesota living with heart failure questionnaire: Reliability and validity during a randomized, double-blind, placebo-controlled trial of pimobendan. Pimobendan multicenter research group. Am Heart J. 1992; 124:1017-1025. [PubMed: 1529875] 
39. Cheng CW, Woo KS, Chan JC, Tomlinson B, You JH. Association between adherence to statin therapy and lipid control in hong kong chinese patients at high risk of coronary heart disease. $\mathrm{Br} \mathrm{J}$ Clin Pharmacol. 2004; 58:528-535. [PubMed: 15521901]

40. Dobbels F, De Geest S, van Cleemput J, Droogne W, Vanhaecke J. Effect of late medication noncompliance on outcome after heart transplantation: A 5-year follow-up. J Heart Lung Transplant. 2004; 23:1245-1251. [PubMed: 15539122]

41. Cameron C. Patient compliance: Recognition of factors involved and suggestions for promoting compliance with therapeutic regimens. J Adv Nurs. 1996; 24:244-250. [PubMed: 8858426]

42. Cramer JA. Microelectronic systems for monitoring and enhancing patient compliance with medication regimens. Drugs. 1995; 49:321-327. [PubMed: 7774509]

43. Wu JR, Moser DK, De Jong MJ, Rayens MK, Chung ML, Riegel B, Lennie TA. Defining an evidence-based cutpoint for medication adherence in heart failure. Am Heart J. 2009; 157:285291. [PubMed: 19185635]

44. Mills RM Jr, Haught WH. Evaluation of heart failure patients: Objective parameters to assess functional capacity. Clin Cardiol. 1996; 19:455-460. [PubMed: 8790948]

45. Chui MA, Deer M, Bennett SJ, Tu W, Oury S, Brater DC, Murray MD. Association between adherence to diuretic therapy and health care utilization in patients with heart failure. Pharmacotherapy. 2003; 23:326-332. [PubMed: 12627931]

46. Bouvy ML, Heerdink ER, Urquhart J, Grobbee DE, Hoes AW, Leufkens HG. Effect of a pharmacist-led intervention on diuretic compliance in heart failure patients: A randomized controlled study. J Card Fail. 2003; 9:404-411. [PubMed: 14583903]

47. Laramee AS, Levinsky SK, Sargent J, Ross R, Callas P. Case management in a heterogeneous congestive heart failure population: A randomized controlled trial. Arch Intern Med. 2003; 163:809-817. [PubMed: 12695272]

48. Lopez Cabezas C, Falces Salvador C, Cubi Quadrada D, Arnau Bartes A, Ylla Bore M, Muro Perea N, Homs Peipoch E. Randomized clinical trial of a postdischarge pharmaceutical care program vs regular follow-up in patients with heart failure. Farm Hosp. 2006; 30:328-342. [PubMed: 17298190]

49. Rich MW, Gray DB, Beckham V, Wittenberg C, Luther P. Effect of a multidisciplinary intervention on medication compliance in elderly patients with congestive heart failure. Am J Med. 1996; 101:270-276. [PubMed: 8873488]

50. Schmitz JM, Sayre SL, Stotts AL, Rothfleisch J, Mooney ME. Medication compliance during a smoking cessation clinical trial: A brief intervention using mems feedback. J Behav Med. 2005; 28:139-147. [PubMed: 15957569] 


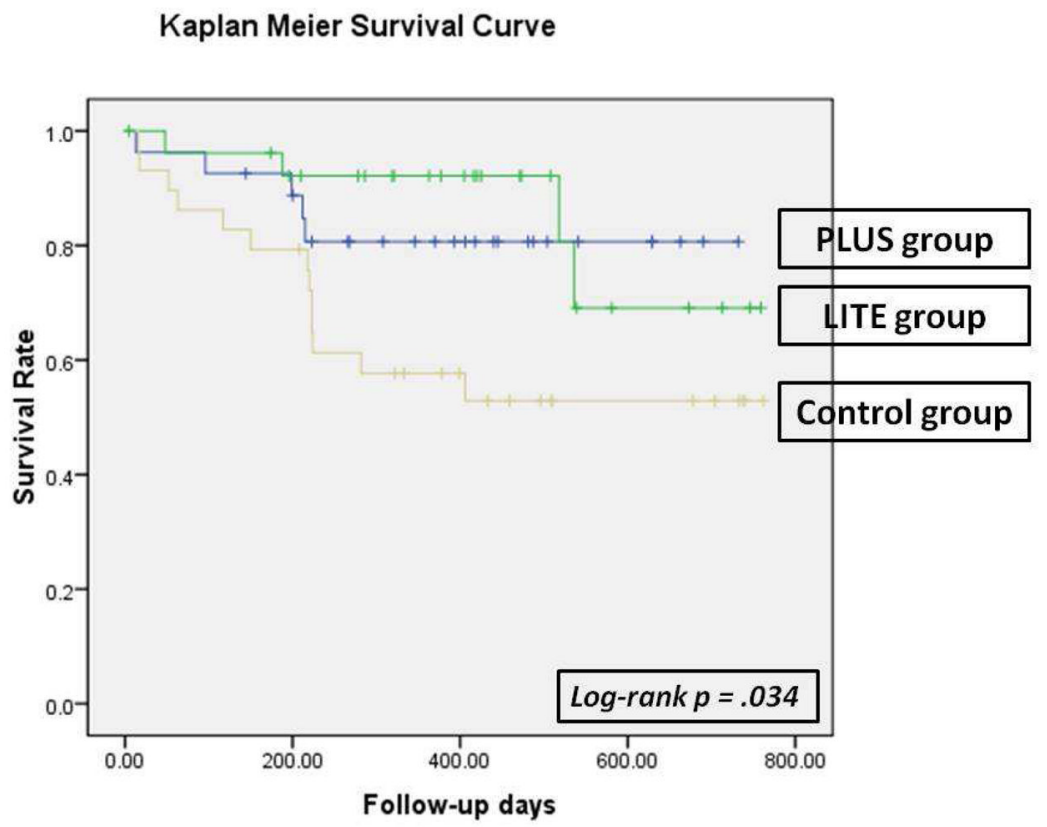

Figure 1.

Time to First Cardiac Event of Emergency Department Visits, Hospitalization, or Mortality among patients in the PLUS, LITE, and control groups 


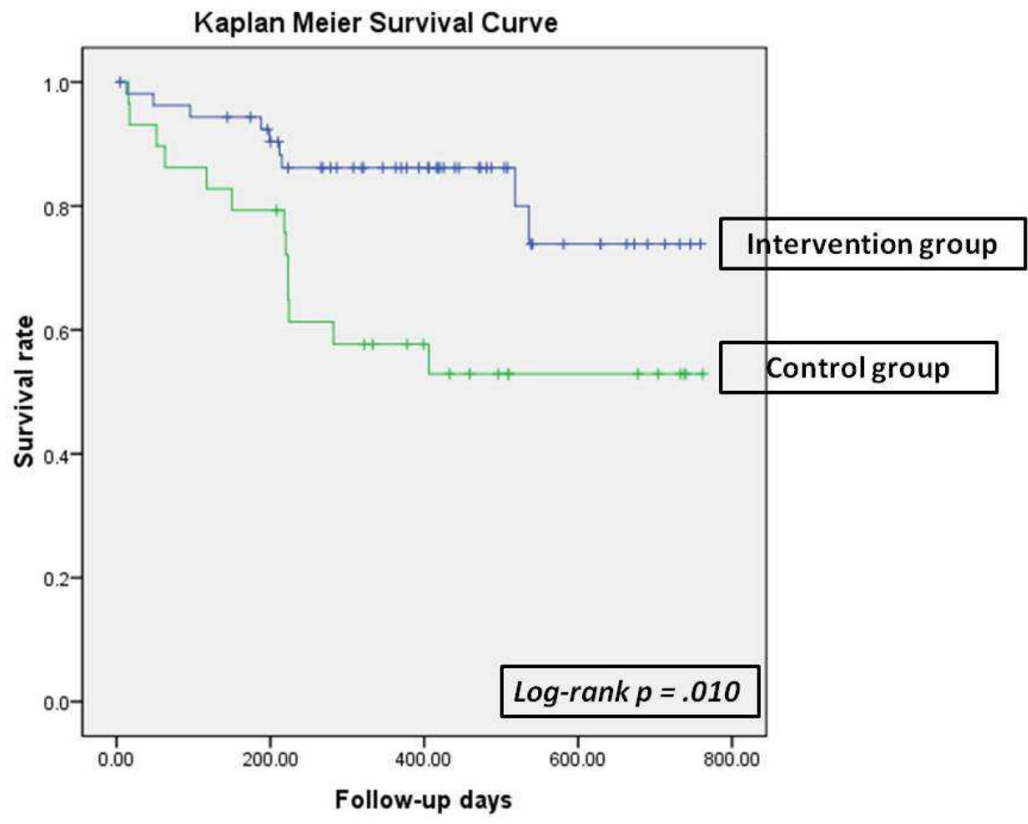

Figure 2.

Time to First Cardiac Event of Emergency Department Visits, Hospitalization, or Mortality between patients in the intervention group and control group 


\section{Quality of Life Score Changes over the Nine Months Period}

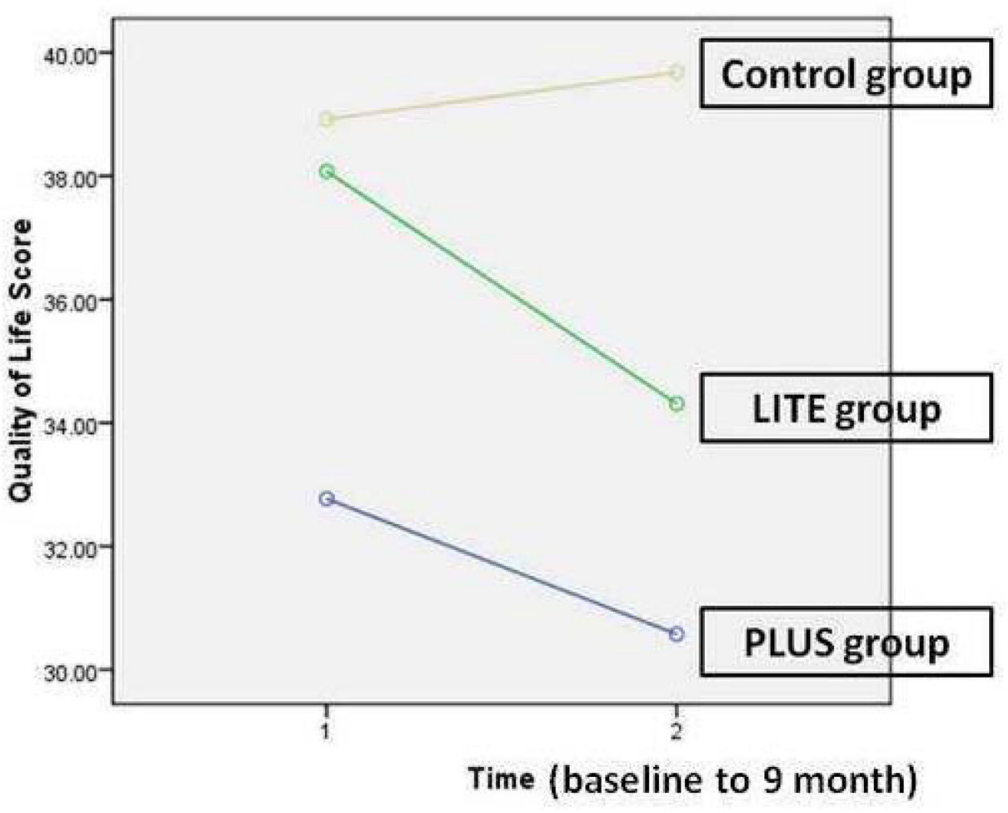

Figure 3.

Quality of life* scores changes from baseline to the end of 9 months period among 3 groups**

*Quality of Life was measure by the Minnesota Living with Heart Failure Questionnaire. Higher scores reflect worse quality of life.

**Repeated measures analysis of variance, no significant difference for time or group by time interaction 
Dose-count adherence changes among 3 groups over the nine months period

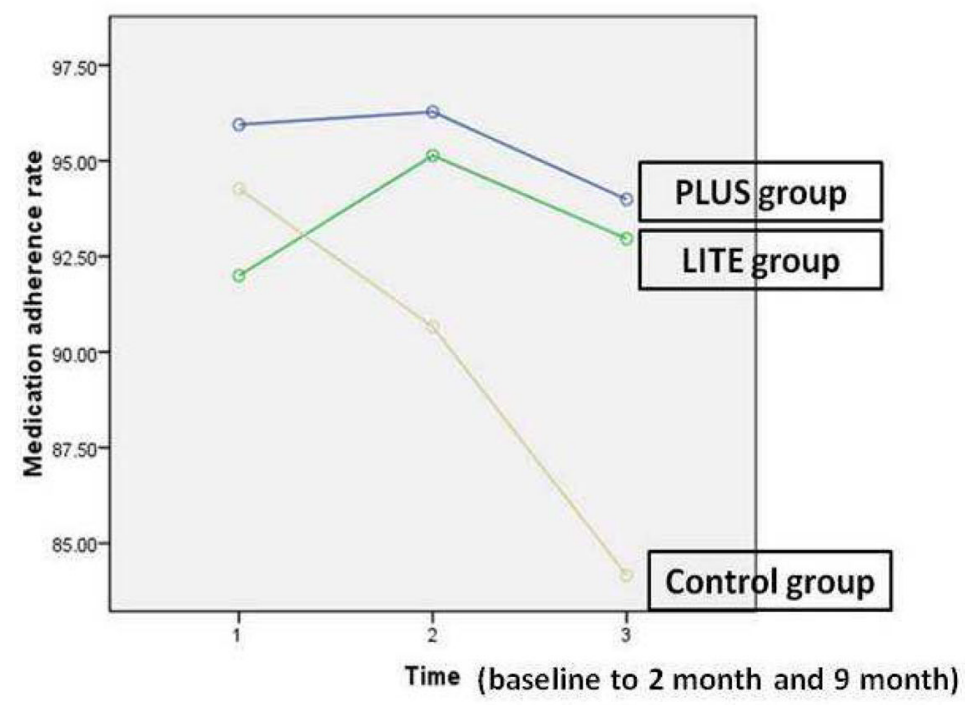

Figure 4.

Dose-count adherence changes over the 9 months period among 3 groups*

* Repeated measures analysis of variance, significant difference for time $(\mathrm{F}=5.405, p=$. $012)$ and group by time interaction $(\mathrm{F}=2.688, p=.05)$ 


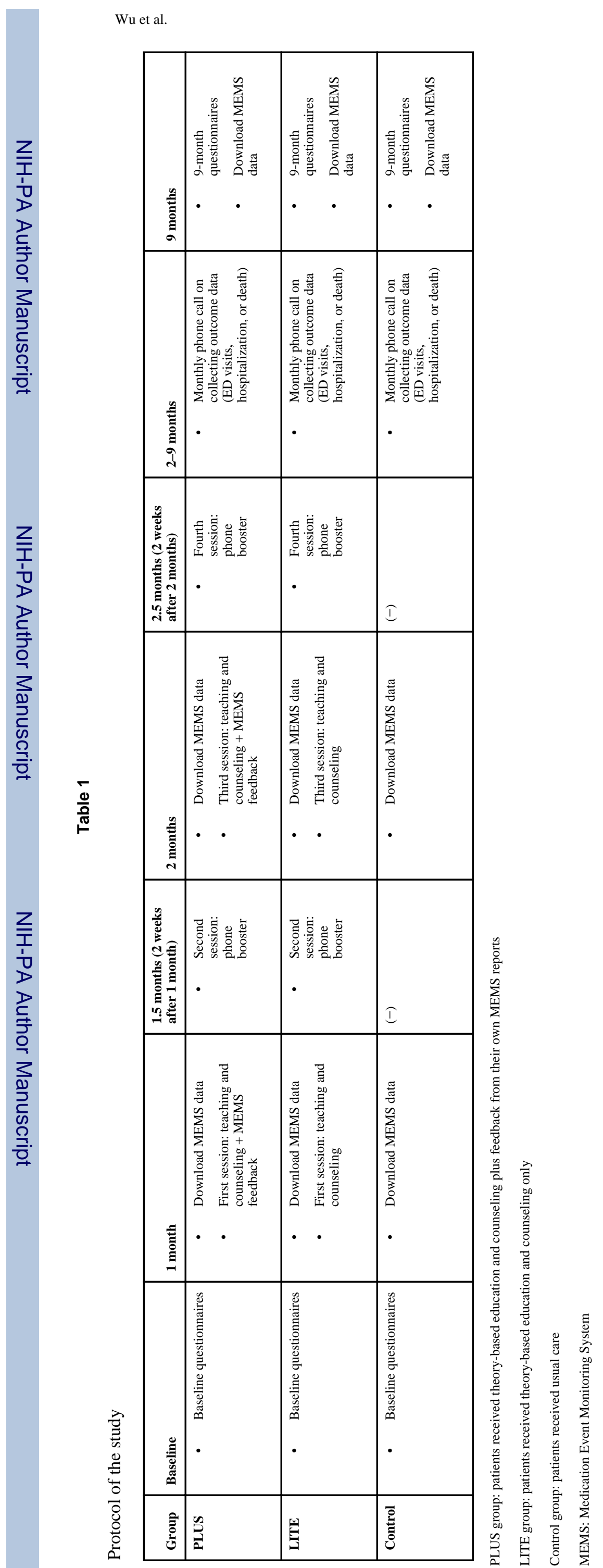

Page 17 


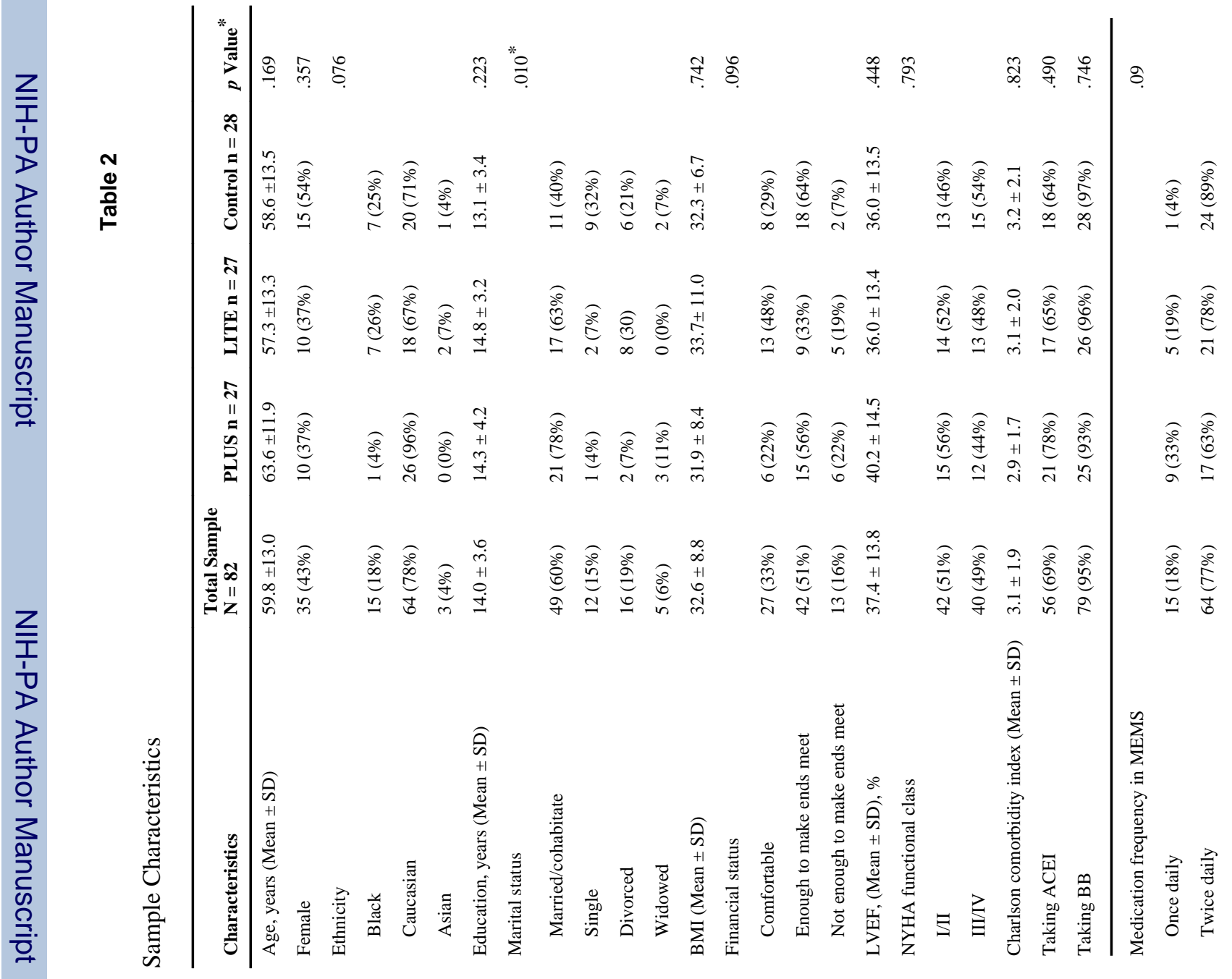

J Card Fail. Author manuscript; available in PMC 2013 January 1. 


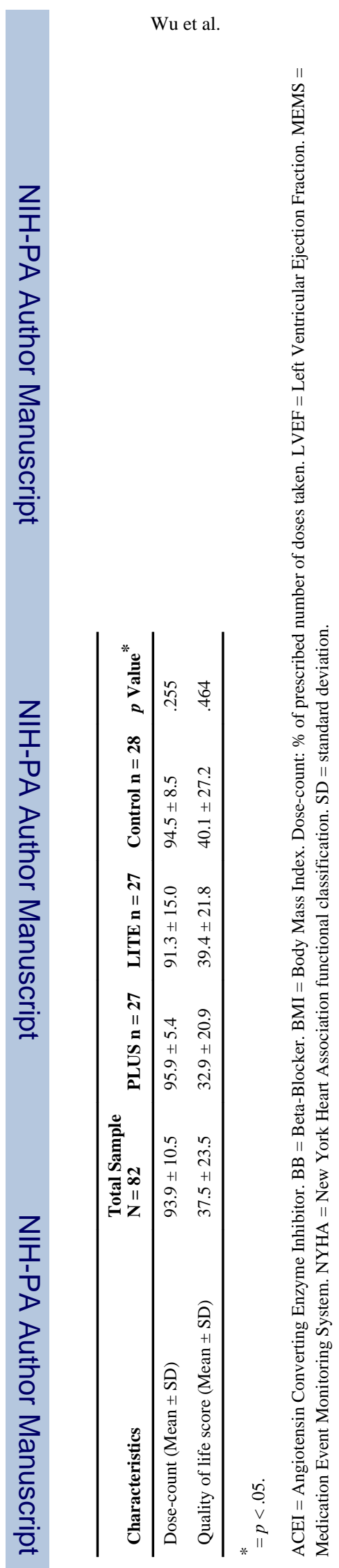

Page 19

J Card Fail. Author manuscript; available in PMC 2013 January 1. 
Table 3

Cox Regression Model: Predictors of Event-free Survival $(\mathrm{N}=82)$

\begin{tabular}{lccc}
\hline Variables & Hazard Ratio & Wald & $p$ \\
\hline *Simple Cox Regression & & & \\
Group (control compared to intervention group) & 2.906 & 6.046 & .014 \\
\hline$* *$ Multiple Cox Regression & & & \\
Group (control compared to intervention group) & 4.223 & 7.677 & .006 \\
Age & .994 & .100 & .752 \\
Marital status & .644 & 3.116 & .078 \\
Financial status & & 9.802 & .007 \\
$\quad$ Enough compared to comfortable & .739 & .241 & .624 \\
$\quad$ Not enough compared to comfortable & 5.156 & 5.626 & .018 \\
Family_company & 1.910 & 1.145 & .285 \\
LVEF & 1.014 & .688 & .407 \\
NYHA (III/IV compared to I/II) & 3.158 & 4.859 & .027 \\
Taking ACEI & .599 & .660 & .417 \\
\hline$* 226.64, p=.010 ;$ & & & \\
$\chi^{2}=6$ & & \\
$\chi^{2}=23.454, p=.012$ \\
ACEI = angiotensin-converting-enzyme inhibitor; LVEF = left ventricular ejection fraction; NYHA = New York Heart Association
\end{tabular}


Table 4

Patients who are adherent ${ }^{*}$ to their prescribed medications in 3 groups over the 9-month period

\begin{tabular}{lcccc}
\hline Duration & PLUS group & LITE group & Control group & Significance $(\boldsymbol{p})$ \\
\hline Baseline & $19(70 \%)$ & $16(59 \%)$ & $18(64 \%)$ & .694 \\
2 month & $22(82 \%)$ & $18(69 \%)$ & $16(59 \%)$ & .203 \\
9 month & $20(74 \%)$ & $17(65 \%)$ & $9(36 \%)$ & .015 \\
\hline
\end{tabular}

Using $88 \%$ as cutpoint to determine whether patients are adherent or non-adherent. 